Manuscript received November 27, 2018; accepted for publication October 1, 2019; published online December 30, 2019. Issue published May 1, 2020.

1 Construction Materials Testing Department, CSI Geo Inc., 2394 St. Johns Bluff Rd. S., Jacksonville, FL 32246, USA (Corresponding author), e-mail: mbazzaz@CSIGeo.com, (1) http://orcid.org/ 0000-0003-1540-3067

2 Department of Civil, Environmental and Architectural Engineering, University of Kansas, 1530 W. 15th St., Lawrence, KS 66045, USA

3 Department of Civil Engineering, Texas A\&M University, 3127 TAMU, College Station, TX 77843, USA

${ }^{4}$ Airport Technology R\&D Branch, William J. Hughes Technical Center, Federal Aviation Administration, Atlantic City International Airport, Atlantic City, NJ 08405, USA, (1) http://orcid. org/0000-0003-1747-4838
Mohammad Bazzaz, ${ }^{1}$ Masoud K. Darabi, ${ }^{2}$ Dallas N. Little, ${ }^{3}$ and Navneet Garg ${ }^{4}$

\section{Effect of Evotherm-M1 on Properties of Asphaltic Materials Used at NAPMRC Testing Facility}

\section{Reference}

M. Bazzaz, M. K. Darabi, D. N. Little, and N. Garg, "Effect of Evotherm-M1 on Properties of Asphaltic Materials Used at NAPMRC Testing Facility," Journal of Testing and Evaluation 48, no. 3 (May/June 2020): 2256-2269. https://doi.org/10.1520/JTE20190446

\section{ABSTRACT}

Rheological properties of asphalt binders significantly affect distress development and performance of asphalt concrete materials. This article presents the effect of Evotherm-M1 modifications on rheological properties of asphalt binders used in the construction of test sections at the Federal Aviation Administration's National Airport Pavement \& Materials Research Center. Four different binders (i.e., polymer styrene butadiene styrene [SBS]-modified PG 76-22, PG 64-22, SBS-modified PG 76-22 plus Evotherm-M1, and PG 64-22 plus Evotherm-M1) are studied. Multiple stress creep recovery (MSCR) and strain-controlled frequency sweep (FS) test results are analyzed to construct the master curves for the binders. Results indicate high sensitivity of SBS-modified PG 76-22 to Evotherm-M1 modifications as compared with PG 64-22. Subsequently, the results of dynamic modulus tests conducted on asphalt mixture specimens (prepared using job mix formula and different binders) are analyzed to investigate the effect of binder type and modification on rheological properties and rutting performance of asphalt mixtures. It is shown that the rutting resistance and rheological properties of asphalt mixtures can be ranked based on the results of MSCR and FS tests conducted on asphalt binders. It is shown that the rutting resistivity of traffic test sections and lab-tested asphalt mixtures can be ranked as follows: SBS-modified PG 76-22, SBS-modified PG 76-22 plus Evotherm-M1, PG 6422, and PG 64-22 plus Evotherm-M1. This is consistent with the results obtained for tested asphalt binders.

\section{Keywords}

Evotherm-M1, frequency sweep, multiple stress creep recovery, rutting resistant, National Airport Pavement \& Materials Research Center, styrene butadiene styrene modified, dynamic modulus 


\section{Introduction}

Rutting, one of the most important distresses in asphalt pavements, is defined as a surface depression within the traffic wheel path. Because of its significance, many recent publications have attempted to model the rutting phenomenon utilizing theoretical approaches, among which the readers are referred to the developed anisotropic viscoplastic continuum model, ${ }^{1}$ and the nonlinear rate-dependent model with damage and plasticity in Misra, Singh, and Darabi, ${ }^{2}$ based on granular micromechanics approach. ${ }^{3-5}$ Low viscosity of asphalt binders and elevated temperatures are among many factors that worsen asphalt concrete pavement rutting. ${ }^{6-9}$ One method used to correct this issue is to improve asphalt binder properties ${ }^{10-16}$ through additives such as styrene butadiene styrene (SBS), ${ }^{17,18}$ ground tire rubber, ${ }^{19,20}$ and polyphosphoric acid, ${ }^{21-23}$ which could improve rutting resistance of asphalt pavements. Such modifiers and additives have different effects on the time- and temperature-dependent behavior of the modified asphalt concrete. Therefore, it is imperative to thoroughly study the effect of these modifiers and additives on the properties of asphalt binder and concrete, especially when dealing with high tire pressure.

In order to evaluate the effect of high tire contact stresses, elevated temperatures, polymer modification, and additives to reduce the compaction temperature, the Federal Aviation Administration (FAA) constructed and trafficked different pavement sections at the National Airport Pavement Materials \& Research Center (NAPMRC) in Atlantic City. ${ }^{24}$ The binders used in these test sections included SBS-modified PG 76-22, PG 64-22; SBS-modified PG 76-22 plus Evotherm-M1; and PG 64-22 plus Evotherm-M1. SBS technology modifiers are thought to increase binder stiffness, reduce temperature susceptibility, and improve adhesion and cohesion properties. ${ }^{1,25}$ However, SBS modification often increases stress-dependent behavior of asphalt binders and asphalt concrete materials. ${ }^{26,27}$ The SBS-modified binders usually behave elastically at low stress levels of approximately $100 \mathrm{~Pa}$ and demonstrate high stress dependency as the stress level increases. As one would intuitively expect, although addition of EvothermM1 to binders reduces mixing temperatures, it may increase rutting sensitivity. ${ }^{26,27}$

Evotherm-M1 is among one of the recent products used in warm mix asphalt (WMA) technology. This technology lowered mixing and compaction temperatures by $30^{\circ} \mathrm{C}-50^{\circ} \mathrm{C}$ compared with conventional hot mix asphalt. It is argued that the addition of the chemical additives to the asphalt mixture (e.g., EvothermM1) improves the aggregate-binder adhesion and reduces the binder viscosity. Reduction of viscosity increases the workability of the asphalt mixture at a lower temperature. ${ }^{28}$ There is limited information available on the long-term performance of WMA. It is claimed that WMA usage reduces fuel consumption and its associated emissions. In addition, other benefits such as improvement of mixtures compactability with lower energy consumption, overall reduction in air voids, ability to pave at lower temperatures after longer haul distances, and using higher percentages of reclaimed asphalt pavement are mentioned in the literature. ${ }^{29}$ However, the authors of this manuscript have some concerns that addition of Evotherm-M1 may affect the resilient modulus or increase the rutting potential of an asphalt mixture.

In this study, the effect of Evotherm-M1 on rheological properties of asphalt binders and mixtures was evaluated through several laboratory tests. The authors conducted multiple stress creep recovery (MSCR) and frequency sweep (FS) tests ${ }^{9,30-32}$ to assess rheological and stress-dependent properties of binders. The effect of strain level in the nonlinear stress-dependent behavior was captured through application of the ChristensenAnderson mathematical mode ${ }^{33}$ under shear-oscillating loading at different frequencies, temperatures, and strain levels. ${ }^{34}$ The authors also evaluated the effect of Evotherm-M1 on asphalt mixture structural performance by analyzing dynamic modulus test data on asphalt concrete mixtures.

\section{Testing Procedures}

\section{PROPERTIES OF THE USED MATERIALS}

There are four different asphalt mixtures at the FAA's NAPMRC testing facility. These mixtures consist of the same aggregate blend. This blend is provided based on the job mix formula (JMF). The aggregate blend used as a surface course with a nominal maximum aggregate size of $19 \mathrm{~mm}$. Also, it contains $8 \%$ natural sand, $36 \%$ \#10 stone, $26 \%$ 
FIG. 1

Sieve analysis for Limestone aggregate were used in the NAPMRC testing facility based on JMF.

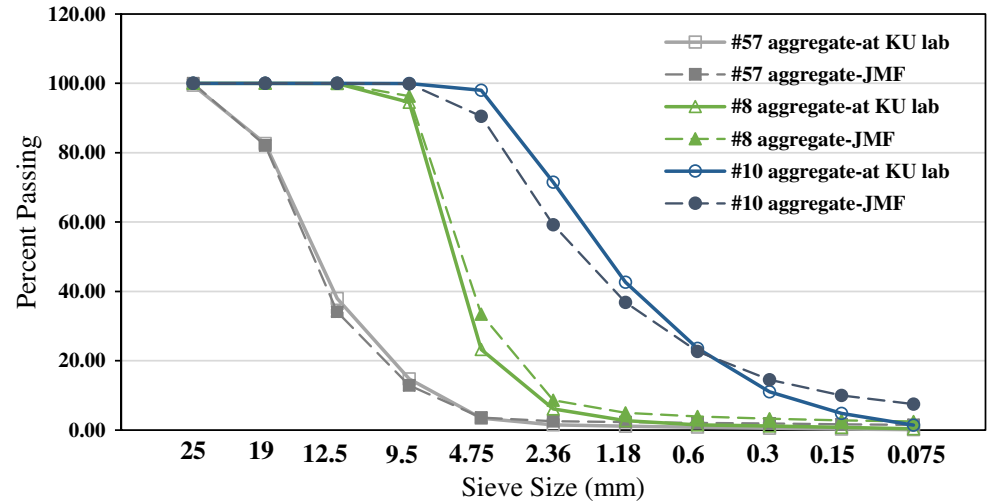

\#8 stone, and $30 \%$ \#57 stone. The sieve size used was American wire gauge. Figure 1 presents the sieve analysis for limestone aggregate used in the NAPMRC testing facility based on JMF. The only difference among the mixtures was the asphalt binders. Four asphalt binders of polymer SBS-modified PG 76-22, PG 64-22, polymer SBS-modified PG 76-22 plus $0.5 \%$ Evotherm-M1, and PG 64-22 plus $0.4 \%$ Evotherm-M1 were used in this study.

Table 1 summarizes the basic properties of the asphalt binders according to JMF and based on ASTM standards. Furthermore, the same binder percentage of $6 \%$ was used in all four mixtures. Table 2 presents the mixture properties used in this study. The mixing and compaction temperatures for all mixtures are given in Table 3, and they were based on JMF from the FAA's NAPMRC testing facility.

\section{SPECIMEN PREPARATION}

\section{Preparation of the Binder Samples}

All binders were shipped from the FAA's NAPMRC testing facility to the University of Kansas and Texas A\&M University asphalt laboratories. The binder was warmed to mixing temperatures, at which point Evotherm-M1 was added. This ensured that all the handling equipment was at the operating temperature. Then, the appropriate amount of Evotherm-M1 was weighted and mixed into the mixtures, comprising the standard FAA's JMF. The mix temperature was closely monitored to ensure the proper target temperatures for addition of the warm mix additive. Asphalt binder properties will change during and after pavement construction. Therefore, the grade selection was conducted on the unaged binders as well as on short-term and long-term aged binders, respectively, based on rolling thin-film oven (RTFO) and pressure aging vessel (PAV) testing.

The RTFO test was used to measure the effect of heat and air on a moving film of asphalt binder. The effects of this treatment were determined from measurements of the properties of the asphalt binder before and after the test in accordance with ASTM D2872-12, Standard Test Method for Effect of Heat and Air on a Moving Film of Asphalt (Rolling Thin-Film Oven Test). The residue from this test was used for additional testing as required in ASTM D6373-16, Standard Specification for Performance Graded Asphalt Binder. The remaining material from the RTFO test simulates the condition of the asphalt binder immediately after the pavement is constructed. This method can be used to determine mass change, which is a measure of asphalt binder volatility resulting from oxidation. At least two replicates were tested for each asphalt binder type with a coefficient of variation of less than $10 \%$, which resulted in eight acceptable tests. The PAV was used to simulate the changes in rheology occurring in asphalt binders during in-service oxidative aging by using residue from RTFO in accordance with the ASTM D6521-18, Standard Practice for Accelerated Aging of Asphalt Binder Using a Pressurized Aging Vessel (PAV). The Results and Discussion section describes the results for the four asphalt binder types that were used at the FAA's NAPMRC testing facility to determine the low-temperature grade of binders. In addition, the bending beam rheometer was used to evaluate the low-temperature stiffness of the binders. 
TABLE 1

The basic properties of binders and binders plus additive used at the NAPMRC testing facility

\begin{tabular}{|c|c|c|c|c|c|c|c|}
\hline Test Type & Properties & PG 76-22 & $\begin{array}{c}\text { PG } 76-22 \\
\text { Plus } 0.5 \% \\
\text { Evotherm }\end{array}$ & PG 64-22 & $\begin{array}{c}\text { PG } 64-22 \\
\text { Plus } 0.4 \% \\
\text { Evotherm }\end{array}$ & Unit & Description \\
\hline \multicolumn{8}{|l|}{ Unaged binder } \\
\hline \multirow{4}{*}{ ASTM D3289-17 } & Specific gravity @ $25^{\circ} \mathrm{C}\left(77^{\circ} \mathrm{F}\right)$ & 1.040 & 1.037 & 1.036 & 1.033 & ${ }^{\circ} \mathrm{API}$ & \\
\hline & Specific gravity @ $15^{\circ} \mathrm{C}\left(60^{\circ} \mathrm{F}\right)$ & 1.046 & 1.043 & 1.041 & 1.037 & & Calculation \\
\hline & API gravity @ $15^{\circ} \mathrm{C}\left(60^{\circ} \mathrm{F}\right)$ & 3.6 & 4.1 & 4.4 & 5 & & Calculation \\
\hline & $\mathrm{kg} / \mathrm{L}$ & 1.038 & 1.041 & 1.039 & 1.035 & & Calculation \\
\hline \multirow[t]{4}{*}{ ASTM D92-18 } & Flash point & 272 & 293 & 260 & 274 & ${ }^{\circ} \mathrm{C}$ & Min. 230 \\
\hline & Viscosity@ $135^{\circ} \mathrm{C}$ & 1.252 & 1.215 & 0.463 & 0.423 & $\mathrm{~Pa} \cdot \mathrm{s}$ & Max. 3.0 \\
\hline & Viscosity @ $165^{\circ} \mathrm{C}$ & 0.313 & 0.303 & 0.133 & 0.123 & $\mathrm{~Pa} \cdot \mathrm{s}$ & Report \\
\hline & Lab mixing temp ${ }^{\circ} \mathrm{C}$, min & 157 & $\ldots$ & 152 & $\ldots$ & ${ }^{\circ} \mathrm{C}$ & Calculation \\
\hline \multirow{5}{*}{ ASTM D4402/D4402M-15 } & Lab mixing temp ${ }^{\circ} \mathrm{C}, \max$ & 163 & $\ldots$ & 157 & $\ldots$ & ${ }^{\circ} \mathrm{C}$ & Calculation \\
\hline & Lab mixing temp ${ }^{\circ} \mathrm{C}$, value & 160 & 135 & 154 & 135 & ${ }^{\circ} \mathrm{C}$ & Calculation \\
\hline & Lab compaction temp ${ }^{\circ} \mathrm{C}$, min & 152 & $\ldots$ & 141 & $\ldots$ & ${ }^{\circ} \mathrm{C}$ & Calculation \\
\hline & Lab compaction temp ${ }^{\circ} \mathrm{C}, \max$ & 157 & $\ldots$ & 146 & $\ldots$ & ${ }^{\circ} \mathrm{C}$ & Calculation \\
\hline & Lab compaction temp ${ }^{\circ} \mathrm{C}$, value & 152 & 130 & 141 & 130 & ${ }^{\circ} \mathrm{C}$ & Calculation \\
\hline \multirow{2}{*}{ ASTM D7175-15 } & ODSR test temp & 76 & 76 & 64 & 64 & ${ }^{\circ} \mathrm{C}$ & \\
\hline & $G^{*} / \sin \delta$ & 1.13 & 1.20 & 1.28 & 1.49 & $\mathrm{kPa}$ & Min. 1.00 \\
\hline \multicolumn{8}{|l|}{ RTFO-aged binder } \\
\hline ASTM D2872-12 & Mass change & -0.413 & -0.224 & -0.562 & -0.111 & Wt.\% & Max. \pm 1.0 \\
\hline \multirow{2}{*}{ ASTM D7175-15 } & RTFO DSR test temp & 76 & 76 & 64 & 64 & ${ }^{\circ} \mathrm{C}$ & \\
\hline & $G^{*} / \sin \delta$ & 2.23 & 2.54 & 3.32 & 3.92 & $\mathrm{kPa}$ & Min. 2.20 \\
\hline \multicolumn{8}{|l|}{ PAV-aged binder } \\
\hline \multirow{3}{*}{ ASTM D7175-15 } & PAV DSR test temp & 31 & 31 & 25 & 25 & ${ }^{\circ} \mathrm{C}$ & \\
\hline & $G^{\star} \sin \delta$ & 2,156 & 2,388 & 2,340 & 3,130 & $\mathrm{kPa}$ & Max. 5,000 \\
\hline & BBR test temp & -12 & -12 & -12 & -12 & ${ }^{\circ} \mathrm{C}$ & \\
\hline \multirow[t]{2}{*}{ ASTM D6648-08 ${ }^{\mathrm{d}}$} & Creep stiffness@60s & 214 & 266 & 118 & 180 & $\mathrm{MPa}$ & Max. 300 \\
\hline & m-value@60 s & 0.363 & 0.316 & 0.395 & 0.351 & & Min. 0.300 \\
\hline
\end{tabular}

Note: $\mathrm{BBR}=$ bending beam rheometer; ODSR = original binder dynamic shear rheometer; ${ }^{\text {a }}$ ASTM D3289-17, Standard Test Method for Density of

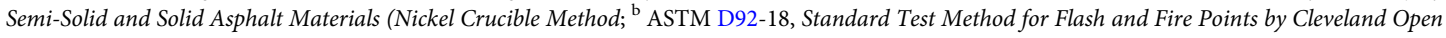
Cup Tester; ${ }^{\mathrm{C}}$ ASTM D7175-15, Standard Test Method for Determining the Rheological Properties of Asphalt Binder Using a Dynamic Shear Rheometer; d ASTM D6648-08, Standard Test Method for Determining the Flexural Creep Stiffness of Asphalt Binder Using the Bending Beam Rheometer (BBR).

TABLE 2

Asphalt mixture properties used at the NAPMRC testing facility based on JMF of FAA

\begin{tabular}{lcccc}
\hline Material & Source & $\begin{array}{c}\text { Percent Used in } \\
\text { Final Aggregate Blend }\end{array}$ & $\begin{array}{c}\text { Bulk Specific } \\
\text { Gravity }\left(G_{\text {sb }}\right)\end{array}$ & $\begin{array}{c}\text { Maximum Specific } \\
\text { Gravity of the Mix }\left(G_{\mathrm{mm}}\right)\end{array}$ \\
\hline Coarse aggregate \#57 & Springhouse, Springhouse, PA & 30 & 2.697 & \\
Coarse aggregate \#10 & Springhouse, Springhouse, PA & 36 & 2.619 & 2.657 \\
Coarse aggregate \#8 & Springhouse, Springhouse, PA & 26 & 2.673 & 2.628 \\
Fine aggregatenatural sand & Hanson, Berlin, NJ & 8 & 1.039 & 2.467 \\
Binder & PG 64-22 & 6 & 1.033 & 2.477 \\
& PG 76-22 & & & \\
\hline
\end{tabular}

\section{Preparation of the Mixture Specimens}

Superpave gyratory compactor was used to prepare the cylindrical specimens in the laboratory. The cylindrical specimens were compacted to $150-\mathrm{mm}$ diameter by $180-\mathrm{mm}$ height. The compactor was tilted and the specimen molded at an internal angle of $1.16^{\circ} \pm 0.02^{\circ}(20.2 \pm 0.35 \mathrm{mrad})$. This was made to ensure uniform distribution of 
TABLE 3

Mixing and compaction temperature along with target air voids for the all mixtures were used at the NAPMRC testing facility based on JMF

\begin{tabular}{lcccc}
\hline Mixture & Binder & Mixing Temperature & Compaction Temperature & Air Voids \\
\hline \multirow{3}{*}{ Hot mix asphalt } & PG 76-22 & $160^{\circ} \mathrm{C}\left(320^{\circ} \mathrm{F}\right)$ & $152.2^{\circ} \mathrm{C}\left(306^{\circ} \mathrm{F}\right)$ & 3.5 \\
& PG 64-22 & $154.4^{\circ} \mathrm{C}\left(310^{\circ} \mathrm{F}\right)$ & $141.1^{\circ} \mathrm{C}\left(286^{\circ} \mathrm{F}\right)$ & 3.1 \\
\multirow{2}{*}{ Warm mix asphalt } & PG 76-22 & $135^{\circ} \mathrm{C}\left(275^{\circ} \mathrm{F}\right)$ & $129.4^{\circ} \mathrm{C}\left(265^{\circ} \mathrm{F}\right)$ & 3.5 \\
& PG 64-22 & $135^{\circ} \mathrm{C}\left(275^{\circ} \mathrm{F}\right)$ & $129.4^{\circ} \mathrm{C}\left(265^{\circ} \mathrm{F}\right)$ & 3.1 \\
\hline
\end{tabular}

air voids within the specimen. The specimens were cored and cut to a $100-\mathrm{mm}$ diameter and $150-\mathrm{mm}$ height. The air void content was determined in accordance with ASTM D3203/D3203M-17, Standard Test Method for Percent Air Voids in Compacted Asphalt Mixtures. These asphalt mixtures contain $4.5 \%$ air void content for polymer SBSmodified PG 76-22 and 3.5\% air void content for PG 64-22 cored specimens. A tolerance of $\pm 0.5 \%$ from the target air voids was targeted. At least two specimens were tested at each condition. Figure 2 summarizes specimen preparation steps.

FIG. 2 Specimen preparation steps: (A) Superpave gyratory compactor compacted the mixtures, (B) 15-cm diameter by 17.8- $\mathrm{cm}$ tall specimens, $(C)$ coring the specimens to $10.2-\mathrm{cm}$ diameter, $(D)$ cutting the specimens to $15.2 \mathrm{~cm}$ high, $(E)$ jig saw cored and cut specimens, $(F$ ) final specimen.

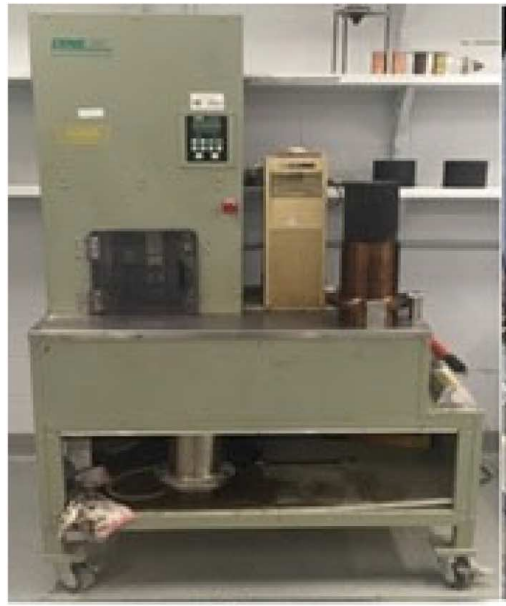

$(A)$

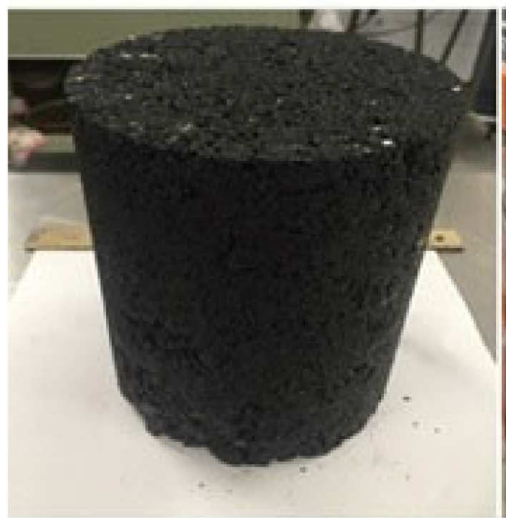

(B)

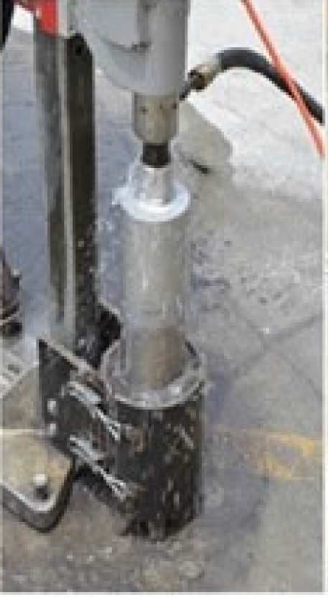

$(C)$

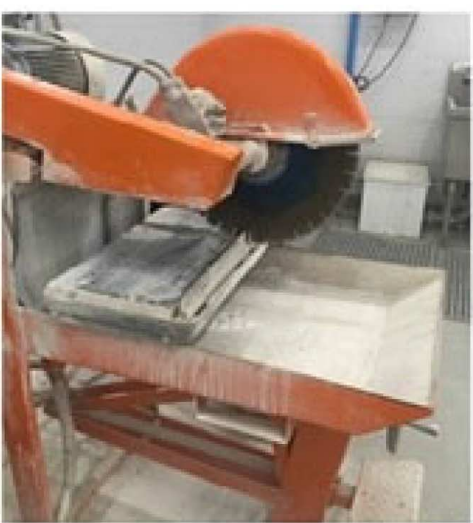

$(D)$

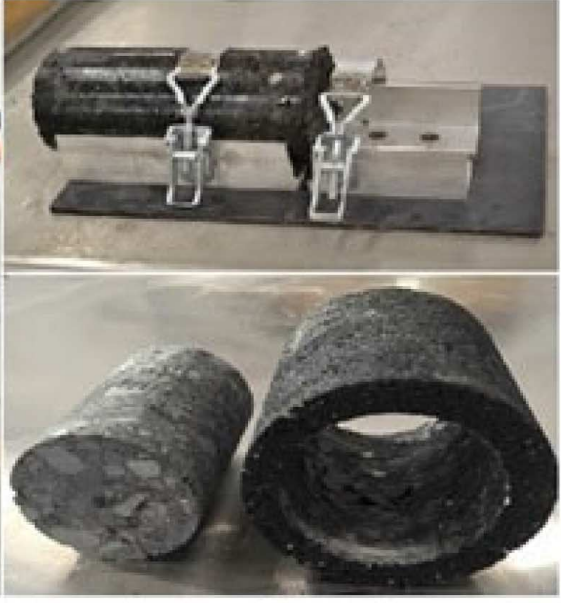

$(E)$

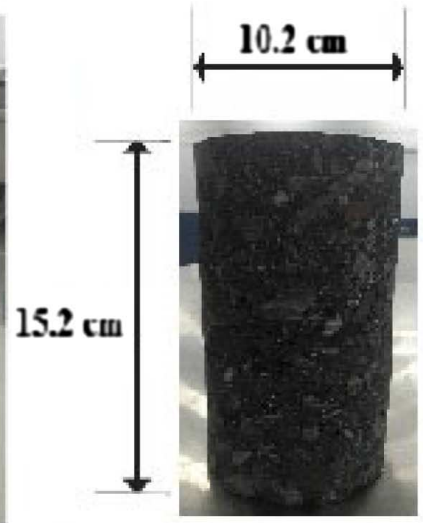

$(F)$ 


\section{TEST PROCEDURE}

A series of experimental tests was conducted to characterize and compare rheological properties and stressdependent behavior of asphalt binders and mixtures with and without Evotherm-M1 additive. These tests are described in the following sections.

\section{Binder Tests}

\section{MSCR Tests}

The MSCR test was performed on RTFO-aged binders according to ASTM D7405-15, Standard Test Method for Multiple Stress Creep and Recovery (MSCR) of Asphalt Binder Using a Dynamic Shear Rheometer, to determine percent recovery and nonrecoverable creep compliance of asphalt binders at $64^{\circ} \mathrm{C}$ using the dynamic shear rheometer (DSR). The percent recovery value (i.e., $R$ ) identifies the elastic response of asphalt binders. Nonrecoverable creep compliance (i.e., $J_{n r}$ ) indicates the resistance of asphalt binder to permanent deformation under repeated loading. The binder is subjected to 30 creep and recovery cycles in total, including an initial 20 cycles at a stress level of $0.1 \mathrm{kPa}$ followed by 10 cycles at a stress level of $3.2 \mathrm{kPa}$. The result of the second and third 10 cycle sequences were used to determine the nonrecoverable creep compliance and percent recovery. The creep portion of the test lasted for 1 second, followed by a 9-second recovery.

\section{Strain-Controlled FS Tests}

The strain-controlled FS tests were conducted on all NAPMRC asphalt binders to measure the dynamic shear modulus and phase angle. The DSR was used to perform FS tests in oscillatory shear using the parallel plate test geometry. These tests were performed to produce master curves for each binder. Tests were conducted on shortterm aged binders in accordance with ASTM D2872-13. The frequencies for the shear-oscillating loading were $37.5,30,25,20,15,10,5,1,0.5$, and $0.1 \mathrm{~Hz}$ at each temperature and strain level. Test temperatures were $10^{\circ} \mathrm{C}$, $20^{\circ} \mathrm{C}, 30^{\circ} \mathrm{C}, 40^{\circ} \mathrm{C}, 50^{\circ} \mathrm{C}, 60^{\circ} \mathrm{C}$, and $70^{\circ} \mathrm{C}$. The reference temperature was arbitrarily chosen to be $20^{\circ} \mathrm{C}$. The $8-\mathrm{mm}$ parallel plate test geometry with a $2-\mathrm{mm}$ working gap was used for testing at $10^{\circ} \mathrm{C}, 20^{\circ} \mathrm{C}$, and $30^{\circ} \mathrm{C}$ test temperatures, and the $25-\mathrm{mm}$ parallel plate test geometry with a $1-\mathrm{mm}$ working gap was used for testing at $40^{\circ} \mathrm{C}, 50^{\circ} \mathrm{C}$, $60^{\circ} \mathrm{C}$, and $70^{\circ} \mathrm{C}$. The linear viscoelastic strain limit was chosen based on the suggestions of Reinke. ${ }^{35}$ At least two replicates with a coefficient of variation less than $10 \%$ along with two samples for each plate size were tested for each asphalt binder type, which resulted in 16 acceptable tests.

\section{Mixture Tests}

\section{Dynamic Modulus Tests}

To identify linear viscoelastic material properties such as Prony series coefficients and time-temperature shift factors, the dynamic modulus test was conducted and analyzed. The AASHTO T 342, Standard Method of Test for Determining Dynamic Modulus of Hot Mix Asphalt (HMA), was followed in the experiments. Three axial linear variable differential transformers (LVDTs) mounted radially on the specimen inside of an Asphalt Mixture Performance Tester (AMPT). The spacing between the LVDTs was $120^{\circ}$ to capture axial strain responses during testing. Five different temperatures of $-10^{\circ} \mathrm{C}, 4.4^{\circ} \mathrm{C}, 21.1^{\circ} \mathrm{C}, 37.8^{\circ} \mathrm{C}$, and $54.4^{\circ} \mathrm{C}$ were chosen to conduct the test. Six loading frequencies of $25,10,5,1,0.5$, and $0.1 \mathrm{~Hz}$ were used at each temperature. To avoid damage and ensure that the responses remained within the linear viscoelastic region, applied strain level was chosen between 50 and $75 \mu \varepsilon$ using a linear amplitude sweep test. ${ }^{7}$ At least two replicates with coefficient of variation of less than $10 \%$ were tested for each temperature and the averaged values reported.

\section{Results and Discussions}

\section{RTFO TEST RESULTS}

The test data from the RTFO were analyzed to determine the mass loss of the binder when heated in an oven for 85 minutes at $163^{\circ} \mathrm{C}\left(325^{\circ} \mathrm{F}\right)$. In addition, the general relationship mass loss of the sample was obtained. Finally, 
the standard deviation and the acceptable range of the two test results were determined based on ASTM C670-15, Standard Practice for Preparing Precision and Bias Statements for Test Methods for Construction Materials. Table 1 summarizes the test results for all four types of asphalt binders used at the FAA's NAPMRC testing facility.

\section{MSCR TEST RESULTS}

The MSCR test was conducted on RTFO-aged binders according to ASTM D7405-15, including polymer SBSmodified PG 76-22 with and without Evotherm-M1 and PG 64-22 with and without Evotherm-M1. This testing produced results for four binder types, with at least two replicates (coefficient of variation of less than $10 \%$ ), amounting to eight acceptable MSCR tests. Based on the MSCR test results provided in Table 4, the following conclusions can be reached:

- The MSCR test results clearly show that the rheological properties of polymer SBS-modified PG 76-22 were significantly affected when Evotherm-M1 was added. However, addition of Evotherm on the rheological properties of PG 64-22 was not as significant.

- Furthermore, asphalt binder materials used at the FAA's NAPMRC testing facility can be ranked with respect to their resistance to rutting as follows:

- Polymer SBS-modified PG 76-22,

- Polymer SBS-modified PG 76-22 plus Evotherm-M1,

- PG 64-22, and

- PG 64-22 plus Evotherm-M1.

- By adding Evotherm-M1 to the asphalt binders, polymer SBS-modified PG 76-22 shows an increase of $23 \%$ in $J_{n r}$ at the $3.2 \mathrm{kPa}$ stress level. However, the $J_{n r}$ at the $3.2 \mathrm{kPa}$ stress level for PG 64-22 only increases by $9 \%$ with Evotherm-M1 addition. Therefore, it is suspected that the difference between performance related to rutting for polymer SBS-modified PG 76-22 and polymer SBS-modified PG 76-22 plus Evotherm-M1 will be more significant than that of PG 64-22 and PG 64-22 plus Evotherm-M1.

- Polymer SBS-modified PG 76-22 and polymer SBS-modified PG 76-22 plus Evotherm-M1 are highly nonlinear with respect to the applied stress levels. The differences in $J_{n r}$ for polymer SBS-modified PG 76-22 and polymer SBS-modified PG 76-22 plus Evotherm-M1 are much higher than those for PG 64-22 and PG 64-22 plus Evotherm-M1, $55 \%$ as compared with $17 \%$, respectively. Therefore, it is expected that the asphalt mixtures made with polymer SBS-modified PG 76-22 used at the FAA testing facility are more susceptible to the changes in the stress level and tire pressure.

- Polymer SBS-modified PG 76-22 and PG 64-22 can be characterized as heavy binders, whereas polymer SBSmodified PG 76-22 plus Evotherm-M1 and PG 64-22 plus Evotherm-M1 can be regarded as standard binders. The MSCR test results show that $J_{n r}$ at a stress level of $3.2 \mathrm{kPa}$ is less than at $2 \mathrm{kPa}^{-1}$ for polymer SBS-modified PG 76-22 and PG 64-22 binders and is higher than $2 \mathrm{kPa}^{-1}$ for polymer SBS-modified PG 76-22 plus Evotherm-M1 and PG 64-22 plus Evotherm-M1. Therefore, the neat binders can be graded as heavy binders, and Evotherm-M1 additive binders can be graded as standard binders according to AASHTO M 332, Standard Specification for Performance-Graded Asphalt Binder Using Multiple Stress Creep Recovery (MSCR) Test.

TABLE 4

MSCR test results for all four types of binders used at the FAA's NAPMRC testing facility

\begin{tabular}{|c|c|c|c|c|c|c|}
\hline \multirow[b]{3}{*}{ Binder Type } & \multicolumn{3}{|c|}{ Recovery Portion } & \multicolumn{3}{|c|}{ Nonrecovered Portion } \\
\hline & \multicolumn{2}{|c|}{ Average Recovery, \% } & \multirow{2}{*}{$\begin{array}{l}\text { Percent Difference of } \\
\text { Recovery, \% }\end{array}$} & \multicolumn{2}{|c|}{$\begin{array}{l}\text { Average Nonrecoverable Creep } \\
\text { Compliance }\left(J_{\mathrm{nr}}\right), 1 / \mathrm{kPa}\end{array}$} & \multirow{2}{*}{$\begin{array}{c}\text { Percent Difference of } \\
\left(J_{\text {nr,diff }}\right), \%\end{array}$} \\
\hline & $0.1 \mathrm{kPa}$ & $3.2 \mathrm{kPa}$ & & $0.1 \mathrm{kPa}$ & $3.2 \mathrm{kPa}$ & \\
\hline PG 64-22 & 7.02 & 0.99 & 85.94 & 1.64 & 1.93 & 17.65 \\
\hline PG 64-22 plus Evotherm-M1 & 6.70 & 0.76 & 88.61 & 1.78 & 2.10 & 18.02 \\
\hline PG 76-22 & 32.87 & 9.75 & 70.37 & 1.24 & 1.92 & 55.48 \\
\hline PG 76-22 plus Evotherm-M1 & 29.62 & 6.89 & 76.80 & 1.51 & 2.37 & 57.28 \\
\hline
\end{tabular}


- Polymer SBS-modified PG 76-22 with and without Evotherm-M1 binders show a higher level of elastic response than PG 64-22 with and without Evotherm-M1. The percent recovery values for polymer SBS-modified PG 76-22 with and without Evotherm-M1 are much higher than percent recovery values for PG 64-22 with and without Evotherm-M1 (i.e., $8 \%$ as compared with $1 \%$ at $3.2 \mathrm{kPa}$ ), which is a clear indication that polymer SBS-modified PG 76-22 will manifest more recoverable deformation when subjected to traffic.

\section{STRAIN-CONTROLLED FS TEST RESULTS}

The test data were analyzed based on the model presented by Zeng et al. ${ }^{34}$ to obtain the dynamic shear modulus and phase angle of asphalt binder corresponding to variable temperatures and frequencies. In addition, a general relationship of change in dynamic shear modulus and phase angle was obtained. The percentage of difference of two test results was ultimately determined. The percentage of difference should not exceed $10 \%$ for $10^{\circ} \mathrm{C}, 20^{\circ} \mathrm{C}$, and $30^{\circ} \mathrm{C}$ test temperatures and should not exceed $15 \%$ for $40^{\circ} \mathrm{C}, 50^{\circ} \mathrm{C}, 60^{\circ} \mathrm{C}$, and $70^{\circ} \mathrm{C}$ test temperatures. Figure 3 shows the dynamic modulus versus frequency for all four types of asphalt binders used at the FAA's NAPMRC testing facility.

To characterize the viscoelastic properties of asphalt binder, the Christensen-Anderson model ${ }^{33}$ is used to construct the master curves of aged binders, such that:

$$
G^{*}(f)=\left(G^{*}\right)_{g}\left[1+\left(\frac{f_{c}}{f_{R}}\right)^{k}\right]^{-\frac{m_{e}}{k}}
$$

where $G^{\star}(f)$ is the complex shear modulus at the frequency of $f,\left(G^{*}\right)_{g}$ is the glassy modulus (assumed to be equal to $1 \mathrm{GPa}), k$ and $m_{e}$ are shape parameters and are dimensionless, $f_{c}$ is the crossover frequency at the defined temperature, and $f_{R}$ is the reduced frequency at the defined temperature (i.e., $T_{R}$ ). The $f_{R}$ is a function of shift factor, such that:

$$
f_{R}=f \times 10^{\log a_{T}}
$$

where $\log a_{T}$ is the shift factor as a function of temperature, and $T$ is the test temperature (K). The shift factor presents the shift required for data obtained at each test temperature to align with the data at the reference temperature

FIG. 3 Dynamic modulus versus frequency for all four types of asphalt binders used at the FAA's NAPMRC testing facility.
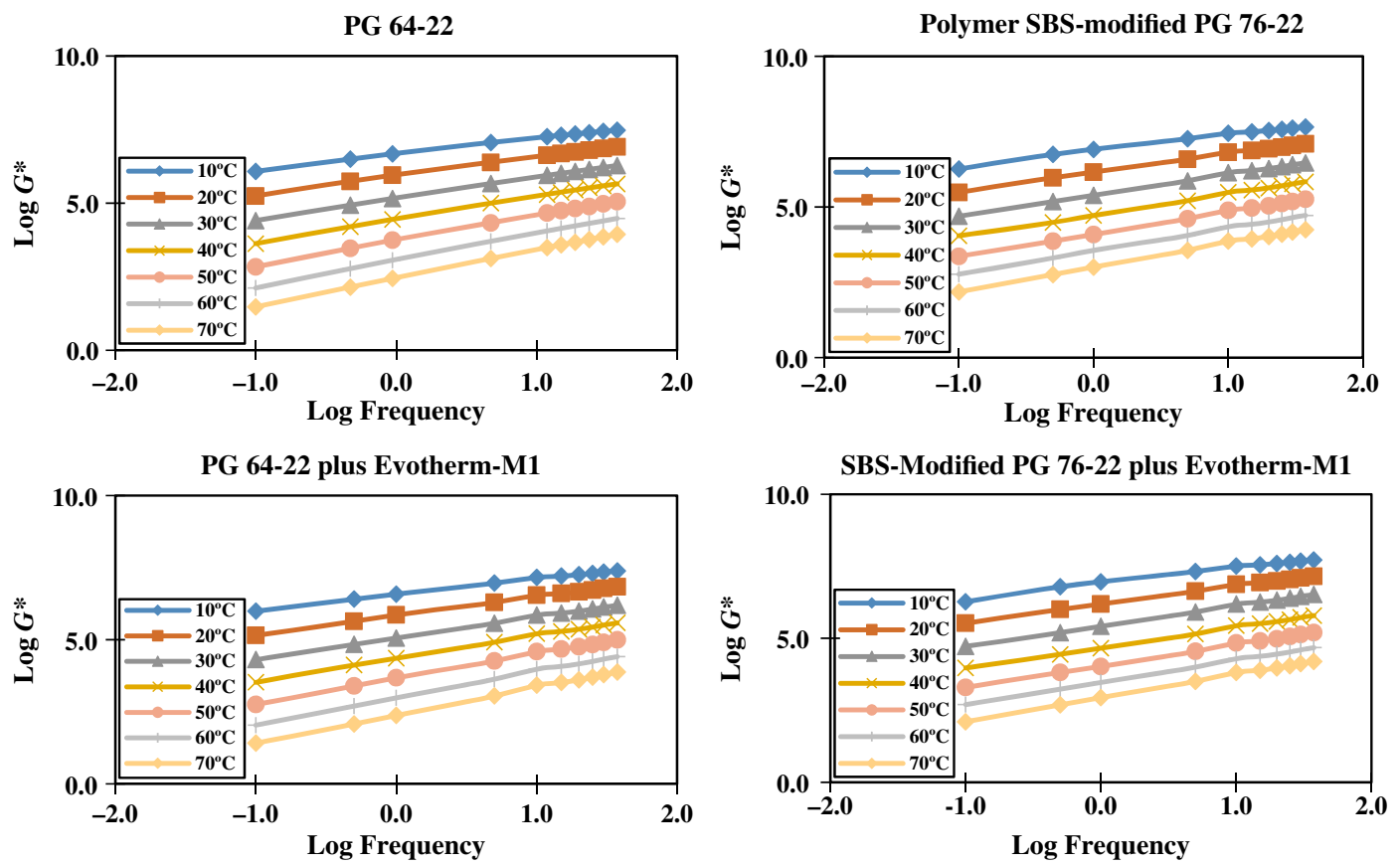
(i.e., $T_{R}$ ). The Williams-Landel-Ferry equation (i.e., equation (3)) was applied to accurately describe the shift factor of asphalt binders. ${ }^{36}$

$$
\log a_{T}=\frac{C_{1}\left(T-T_{R}\right)}{C_{2}+T-T_{R}}
$$

where $C_{1}$ and $C_{2}$ are constants. The rheological parameters $\left(k, m_{e}, f_{c}, C_{1}\right.$, and $\left.C_{2}\right)$ of the Christensen-Anderson model have specific physical significances. Table 5 shows the values of the rheological parameters of the studied binders at the reference temperature, which is arbitrarily chosen to be $20^{\circ} \mathrm{C}$. The value of the crossover frequency $\left(f_{c}\right)$ is related to the overall stiffness of the binder. As the crossover frequency increases, the stiffness of the binder decreases. Binders plus Evotherm-M1 show higher values of crossover frequency as compared with the virgin binders. In other words, the addition of the Evotherm-M1 decreases the stiffness of the virgin binders.

Figure 4 presents the master curves for all four types of asphalt binders used at the FAA's NAPMRC testing facility. To compare the master curves, figure 5 shows the master curves for RTFO-aged binders of FAA's NAPMRC testing facility in the same graph. According to figure 5, the rank order for dynamic moduli (i.e., $G^{\star}$ ) from highest to lowest dynamic modulus can be ranked as follows at low frequencies correlating to high-performance temperatures: polymer SBS-modified PG 76-22, polymer SBS-modified PG 76-22 plus Evotherm-M1, PG 64-22, and PG 64-22 plus Evotherm-M1 at low frequencies. As dynamic modulus increases, recovered strain decreases. This is also in agreement with Witczak's predictive equation. ${ }^{36}$ The Witczak equation is developed between the dynamic modulus and mixture properties based on the data from more than 200 different asphalt mixes, including a wide range of modified asphalts.

Considering the same properties for the asphalt concrete, as asphalt viscosity increases (i.e., $\eta$ ), the asphalt concrete dynamic modulus increases (i.e., $G^{\star}$ ). This change in properties will result in a reduction of recovered strain. Asphalt viscosities of polymer SBS-modified PG 76-22, polymer SBS-modified PG 76-22 plus EvothermM1, PG 64-22, and PG 64-22 plus Evotherm-M1 are 1.505, 1.215, 0.430, and $0.423 \mathrm{~Pa} \cdot \mathrm{s}$, respectively, which were extracted from ASTM D4402/D4402M-15, Standard Test Method for Viscosity Determination of Asphalt at Elevated Temperatures Using a Rotational Viscometer, and presented in the FAA's JMF. As results show in Table 5, the Christensen-Anderson parameters, like crossover frequency and temperature susceptibility, will increase with the addition of Evotherm-M1.

\section{DYNAMIC MODULUS TEST RESULTS}

The complex dynamic modulus (i.e., $E^{\star}(\omega)$ ) and phase angle (i.e., $\delta$ ) at different frequencies and temperatures were analyzed considering $20^{\circ} \mathrm{C}$ as the reference temperature to produce the dynamic modulus master curve. The sigmoidal-type function proposed by Pellinen, Witczak, and Bonaquist ${ }^{37}$ was implemented using a MATLAB code to construct the dynamic modulus master curve. To minimize the error between the model predictions and experimental

\section{TABLE 5}

Rheological properties of binders used at the FAA's NAPMRC testing facility

\begin{tabular}{lcccccc}
\hline & Constant & $\begin{array}{c}\text { Temperature } \\
\text { Constant }\end{array}$ & $\begin{array}{c}\text { Crossover } \\
\text { Frequency }\end{array}$ & $\begin{array}{c}\text { Shape } \\
\text { Parameter }\end{array}$ & $\begin{array}{c}\text { Shape } \\
\text { Parameter }\end{array}$ & $\begin{array}{c}\text { Reference } \\
\text { Temperature }\end{array}$ \\
\cline { 2 - 7 } Binder Type & $\mathrm{C}_{1}$ & $\mathrm{C}_{2}$ & $f_{\mathrm{c}}$ & $k$ & $m_{\mathrm{e}}$ & $T_{\mathrm{R}}$ \\
\hline PG 64-22 & & & & & $\left({ }^{\circ} \mathrm{C}\right)$ \\
PG 64-22 plus Evotherm-M1 & -15.786 & 137.610 & 15.741 & 0.146 & 1.119 & 1.138 \\
PG 76-22 & -15.512 & 139.200 & 16.332 & 0.143 & 0.815 & 20 \\
PG 76-22 plus Evotherm-M1 & -16.119 & 138.387 & 947.673 & 0.194 & 0.814 & \\
\hline
\end{tabular}


FIG. 4 Master curve for RTFO aging of all four types of asphalt binders used at the FAA's NAPMRC testing facility.
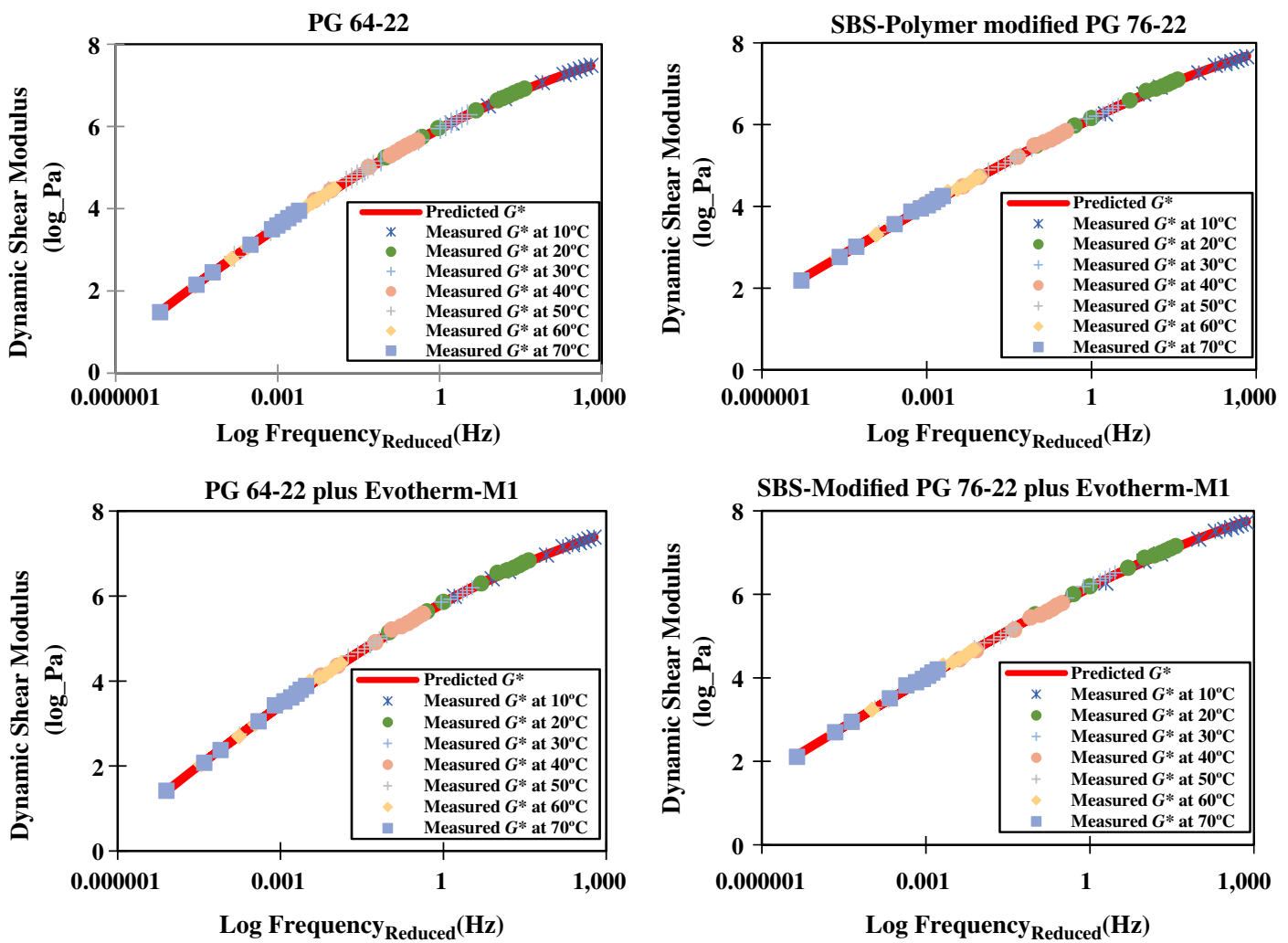

FIG. 5

Master curves for RTFO-

aged binders of

NAPMRC testing facility.

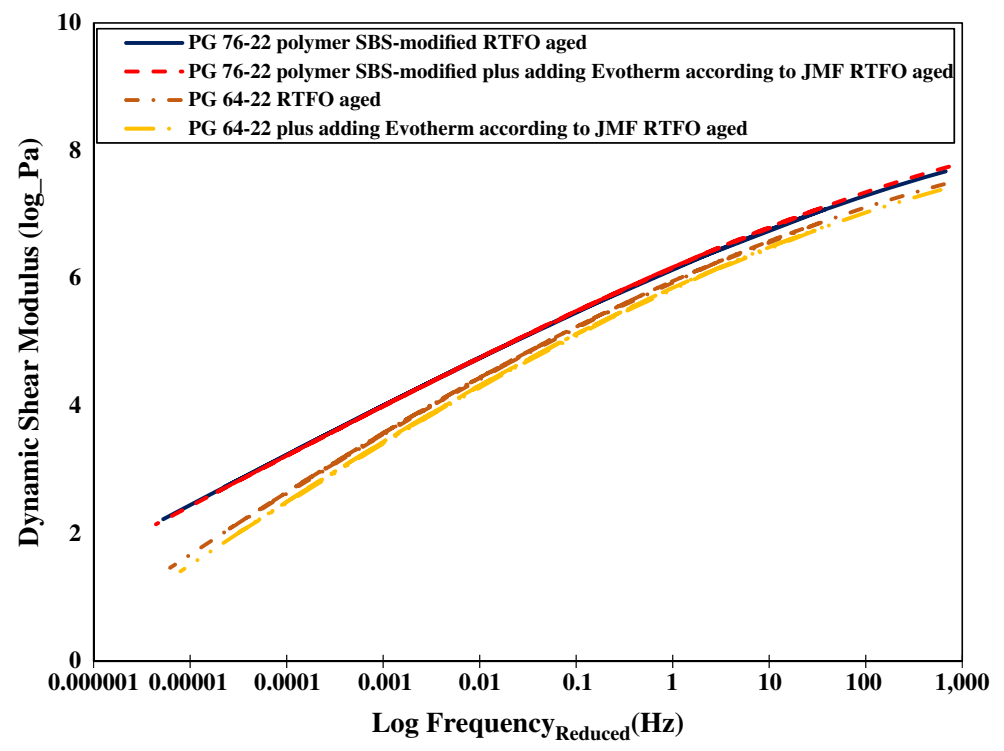

measurements of the storage and loss moduli (i.e, $E_{E x p}^{\prime}(\omega)=\left|E^{\star}(\omega)\right| \cos \delta$ and $E_{E x p}^{\prime \prime}(\omega)=\left|E^{\star}(\omega)\right| \sin \delta$, respectively), the nonlinear generalized reduced gradient method ${ }^{38}$ was applied. The Prony series coefficients were extracted, and the transient compliance is presented in terms of the Prony series, such that: 


$$
\Delta D(t)=\sum_{n=1}^{N} D_{n}\left[1-\exp \left(-\lambda_{n} \psi^{t}\right)\right]
$$

where $D_{n}$ and $\lambda_{n}$ are the nth compliance and retardation time, respectively. $N$ is the number of Prony series components. The term $\psi^{t}=\int_{0}^{t} \frac{d \xi}{a_{T}}$ is the reduced time, whereas $a_{T}$ is the time-temperature shift factor. The constructed master curves for the NAPMRC testing facility asphalt mixtures are shown in figure 6. Using interconversion relationships ${ }^{39}$ between the Prony series coefficients and the loss and storage dynamic compliances, the Prony series coefficients, shown in equation (4), were determined. The identified Prony series coefficients and time-temperature shift factors for the NAPMRC testing facility asphalt mixtures are presented in Table 6.

\section{FIG. 6}

Master curve according to ASTM D3497-79, Standard Test Method for Dynamic Modulus of Asphalt Mixtures (Withdrawn 2009), for the dynamic modulus, $E^{*}$, using the sigmoidal fitting function in log-log scale.

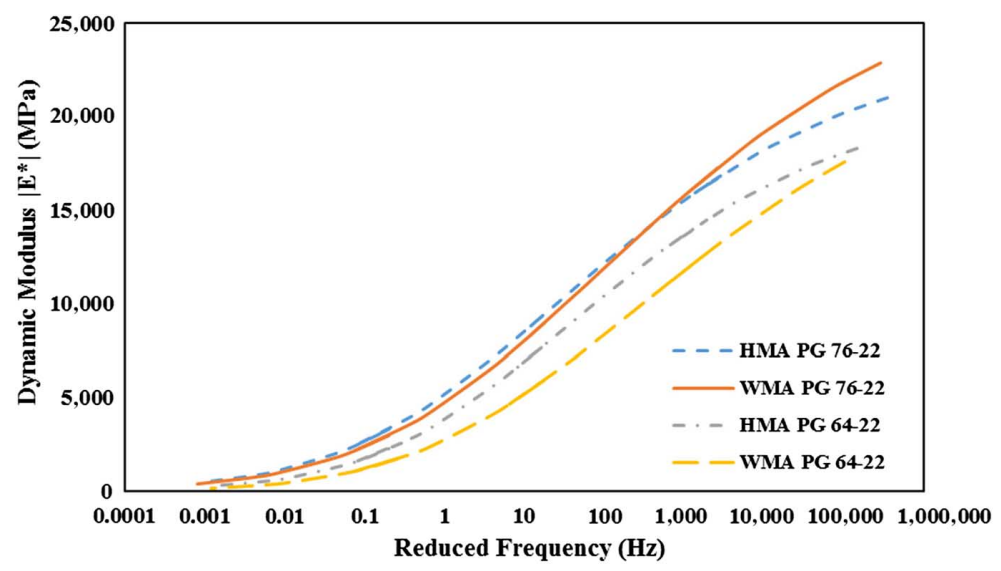

TABLE 6

Nonlinear viscoelastic parameters

\begin{tabular}{|c|c|c|c|c|c|c|c|c|}
\hline \multirow[b]{2}{*}{$n$} & \multicolumn{2}{|c|}{ HMA PG 76-22 } & \multicolumn{2}{|c|}{ WMA PG 76-22 } & \multicolumn{2}{|c|}{ HMA PG 64-22 } & \multicolumn{2}{|c|}{ WMA PG 64-22 } \\
\hline & $D_{n}\left(\mathrm{MPa}^{-1}\right)$ & $\lambda_{n}(1 / \mathrm{s})$ & $D_{n}\left(\mathrm{MPa}^{-1}\right)$ & $\lambda_{n}(1 / \mathrm{s})$ & $D_{n}\left(\mathrm{MPa}^{-1}\right)$ & $\lambda_{n}(1 / \mathrm{s})$ & $D_{n}\left(\mathrm{MPa}^{-1}\right)$ & $\lambda_{n}(1 / \mathrm{s})$ \\
\hline 0 & $5.58 \times 10^{-5}$ & $\ldots$ & $5.63 \times 10^{-5}$ & $\ldots$ & $6.20 \times 10^{-5}$ & $\ldots$ & $3.85 \times 10^{-5}$ & . \\
\hline 1 & $2.54 \times 10^{-5}$ & $4.35 \times 10^{3}$ & $2.37 \times 10^{-5}$ & $4.21 \times 10^{3}$ & $3.70 \times 10^{-5}$ & $1.65 \times 10^{3}$ & $3.54 \times 10^{-5}$ & $7.47 \times 10^{4}$ \\
\hline 2 & $2.73 \times 10^{-5}$ & $4.01 \times 10^{2}$ & $2.40 \times 10^{-5}$ & $3.93 \times 10^{2}$ & $3.89 \times 10^{-5}$ & $1.78 \times 10^{2}$ & $4.33 \times 10^{-5}$ & $5.95 \times 10^{3}$ \\
\hline 3 & $7.23 \times 10^{-5}$ & $3.69 \times 10$ & $6.23 \times 10^{-5}$ & $3.67 \times 10$ & $1.00 \times 10^{-4}$ & $1.92 \times 10$ & $6.91 \times 10^{-5}$ & $4.73 \times 10^{2}$ \\
\hline 4 & $1.45 \times 10^{-4}$ & 3.40 & $1.23 \times 10^{-4}$ & 3.42 & $2.08 \times 10^{-4}$ & 2.07 & $1.52 \times 10^{-4}$ & $3.76 \times 10$ \\
\hline 5 & $4.14 \times 10^{-4}$ & $3.13 \times 10^{-1}$ & $3.43 \times 10^{-4}$ & $3.19 \times 10^{-1}$ & $6.39 \times 10^{-4}$ & $2.24 \times 10^{-1}$ & $3.82 \times 10^{-4}$ & 2.99 \\
\hline 6 & $9.94 \times 10^{-4}$ & $2.88 \times 10^{-2}$ & $8.12 \times 10^{-4}$ & $2.98 \times 10^{-2}$ & $1.26 \times 10^{-3}$ & $2.41 \times 10^{-2}$ & $1.13 \times 10^{-3}$ & $2.38 \times 10^{-1}$ \\
\hline 7 & $2.94 \times 10^{-3}$ & $2.65 \times 10^{-3}$ & $2.41 \times 10^{-3}$ & $2.78 \times 10^{-3}$ & $4.97 \times 10^{-3}$ & $2.60 \times 10^{-3}$ & $3.61 \times 10^{-3}$ & $1.89 \times 10^{-2}$ \\
\hline 8 & $5.96 \times 10^{-3}$ & $2.44 \times 10^{-4}$ & $4.23 \times 10^{-3}$ & $2.59 \times 10^{-4}$ & $8.35 \times 10^{-3}$ & $2.81 \times 10^{-4}$ & $1.77 \times 10^{-2}$ & $1.51 \times 10^{-3}$ \\
\hline 9 & $2.07 \times 10^{-2}$ & $2.25 \times 10^{-5}$ & $1.50 \times 10^{-2}$ & $2.42 \times 10^{-5}$ & $2.44 \times 10^{-2}$ & $3.03 \times 10^{-5}$ & $2.39 \times 10^{-2}$ & $1.20 \times 10^{-4}$ \\
\hline \multicolumn{9}{|c|}{ Shift Parameters } \\
\hline Temp & $a_{T}$ & $\log \left(a_{T}\right)$ & $a_{T}$ & $\log \left(a_{T}\right)$ & $a_{T}$ & $\log \left(a_{T}\right)$ & $a_{T}$ & $\log \left(a_{T}\right)$ \\
\hline-10.0 & $13,762.86$ & 4.1387 & $11,578.01$ & 4.0636 & $5,813.25$ & 3.7644 & $4,023.92$ & 3.6046 \\
\hline 4.4 & 112.96 & 2.0529 & 106.61 & 2.0278 & 76.11 & 1.8815 & 65.54 & 1.8165 \\
\hline 21.1 & 0.7301 & -0.1366 & 0.7311 & -0.1360 & 0.7474 & -0.1265 & 0.7527 & -0.1234 \\
\hline 37.8 & 0.0083 & -2.0799 & 0.0082 & -2.0880 & 0.0113 & -1.9456 & 0.0120 & -1.9194 \\
\hline 54.4 & 0.0002 & -3.7674 & 0.0002 & -3.8184 & 0.0003 & -3.5667 & 0.0003 & -3.5622 \\
\hline
\end{tabular}

Note: $n$ is the number of Prony series components, $D_{n}$ is the compliance time, $\lambda_{n}$ is the retardation time, and $a_{T}$ is the time-temperature shift factor. 
Figure 6 shows the effect of Evotherm-M1 addition on the asphalt mixture properties, and it suggests a reduction of moduli at different frequencies, although the polymer SBS-modified PG 76-22 at high frequencies is an exception. The polymer SBS-modified PG 76-22 shows higher moduli as compared with moduli for PG 64-22, as expected. The impact of Evotherm-M1 on nonlinear viscoelastic parameters is much more pronounced than its impact on linear viscoelastic parameters. For more details please review the reference for Nejadsadeghi and Misra. ${ }^{6}$

\section{Summary and Conclusions}

This study investigated the effect of Evotherm-M1 on rheological properties, stress-dependent behavior, and rutting resistance of the asphalt binders and mixture used at the FAA's NAPMRC testing facility. Appropriate test methods were used to develop master curves and determine percent recovery as well as nonrecoverable creep compliance of asphalt binders. The test data from the RTFO-aged, and PAV-aged binders were analyzed using DSR to grade binders based on the conventional PG Superpave system. In addition, MSCR and strain-controlled FS test data were obtained using DSR on RTFO-aged binders. Dynamic modulus tests were conducted to extract the master curves at mixture level using an AMPT. The authors may add a future study to extend evaluation of Evotherm-M1's effects on the asphalt mixtures' performance. The experimental studies and data analysis presented in this article lead to the following conclusions:

- The rheological properties of polymer SBS-modified PG 76-22 are more variable upon Evotherm-M1 modification compared with the standard binder in the analysis, PG 64-22.

- Addition of Evotherm-M1 causes changes in viscosity of binders, which results in an increase of the rutting potential and a decrease in the mixing and compaction temperatures.

- Asphalt binder materials used at the FAA's NAPMRC testing facility rank with respect to their resistance to rutting for most to least resistant as follows:

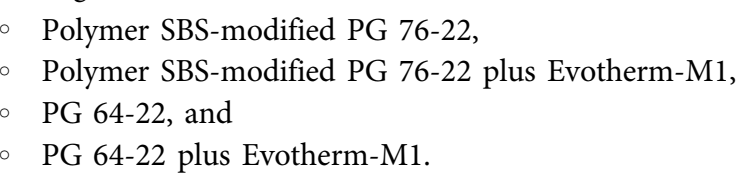

The results are consistent with the traffic test results conducted by the FAA on NAPMRC flexible pavement test sections. ${ }^{24}$ Both base asphalt binders (SBS-modified PG 76-22 and PG 64-22) modified with the Evotherm$\mathrm{M} 1$ additive experienced a reduction in performance based in rheological test properties.

- Addition of Evotherm-M1 to polymer SBS-modified PG 76-22 makes it more susceptible to the changes in the stress level and tire pressure as compared with the same scenario for PG 64-22 binder.

- Polymer SBS-modified PG 76-22 with and without Evotherm-M1 demonstrate more recoverable deformation when subjected to traffic compared with PG 64-22 with and without Evotherm-M1.

- Considering the same properties for the asphalt concretes, tests results show that as asphalt viscosity increases, asphalt concrete dynamic modulus increases, which results in the reduction of recovered strain.

- Addition of the Evotherm-M1 decreases the stiffness of the virgin binders used in this study.

- Polymer SBS-modified PG 76-22 with and without Evotherm-M1 demonstrate more recoverable deformation when subjected to traffic compared with PG 64-22 with and without Evotherm-M1.

\section{ACKNOWLEDGMENTS}

The work described in this article was supported by the FAA's Airport Technology Research and Development Branch through Grant 15-G-011. The contents of this article reflect the views of the authors, who are responsible for the facts and accuracy of the data presented within. The contents do not necessarily reflect the official views and policies of the FAA. The article does not constitute a standard, specification, or regulation. The first author would like to thank CSI Geo, Inc. for their financial support. 


\section{References}

1. L. Tashman, E. Masad, H. Zbib, D. Little, and K. Kaloush, "Microstructural Viscoplastic Continuum Model for Permanent Deformation in Asphalt Pavements," Journal of Engineering Mechanics 131, no. 1 (January 2005): 48-57. https://doi.org/10.1061/(ASCE)0733-9399(2005)131:1(48)

2. A. Misra, V. Singh, and M. K. Darabi, "Asphalt Pavement Rutting Simulated Using Granular Micromechanics-Based Rate-Dependent Damage-Plasticity Model," International Journal of Pavement Engineering 20, no. 9 (September 2019): 1012-1025. https://doi.org/10.1080/10298436.2017.1380804

3. N. Nejadsadeghi, L. Placidi, M. Romeo, and A. Misra, "Frequency Band Gaps in Dielectric Granular Metamaterials Modulated by Electric Field,” Mechanics Research Communications 95 (January 2019): 96-103. https://doi.org/10. 1016/j.mechrescom.2019.01.006

4. A. Misra and N. Nejadsadeghi, "Longitudinal and Transverse Elastic Waves in 1D Granular Materials Modeled as Micromorphic Continua," Wave Motion 90 (August 2019): 175-195. https://doi.org/10.1016/j.wavemoti.2019.05.005

5. H. Özen, "Rutting Evaluation of Hydrated Lime and SBS Modified Asphalt Mixtures for Laboratory and Field Compacted Samples," Construction and Building Materials 25, no. 2 (February 2011): 756-765. https://doi.org/10.1016/j.conbuildmat. 2010.07.010

6. N. Nejadsadeghi and A. Misra, “Axially Moving Materials with Granular Microstructure,” International Journal of Mechanical Sciences 161-162 (October 2019): 105042. https://doi.org/10.1016/j.ijmecsci.2019.105042

7. M. Bazzaz, M. K. Darabi, D. N. Little, and N. Garg, "A Straightforward Procedure to Characterize Nonlinear Viscoelastic Response of Asphalt Concrete at High Temperatures," Transportation Research Record: Journal of the Transportation Research Board 2672, no. 28 (July 2018): 481-492. https://doi.org/10.1177/0361198118782033

8. M. K. Darabi, C.-W. Huang, M. Bazzaz, E. A. Masad, and D. N. Little, "Characterization and Validation of the Nonlinear Viscoelastic-Viscoplastic with Hardening-Relaxation Constitutive Relationship for Asphalt Mixtures," Construction and Building Materials 216 (August 2019): 648-660. https://doi.org/10.1016/j.conbuildmat.2019.04.239

9. M. K. Darabi, R. Kola, D. N. Little, E. Rahmani, and N. Garg, "Predicting Rutting Performance of Flexible Airfield Pavements Using a Coupled Viscoelastic-Viscoplastic-Cap Constitutive Relationship," Journal of Engineering Mechanics 145, no. 2 (February 2019): 04018129. https://doi.org/10.1061/(ASCE)EM.1943-7889.0001516

10. F. Moreno, M. Sol, J. Martín, M. Pérez, and M. C. Rubio, "The Effect of Crumb Rubber Modifier on the Resistance of Asphalt Mixes to Plastic Deformation," Materials \& Design 47 (May 2013): 274-280. https://doi.org/10.1016/j.matdes. 2012.12.022

11. A. Behnood, A. Shah, R. S. McDaniel, M. Beeson, and J. Olek, "High Temperature Properties of Asphalt Binders: Statistical and Experimental Comparison of MSCR and PG Grading Systems," Transportation Research Record: Journal of the Transportation Research Board 2574, no. 1 (January 2016): 131-143. https://doi.org/10.3141/2574-15

12. J. Król, P. Radziszewski, and K. J. Kowalski, "Influence of Microstructural Behavior on Multiple Stress Creep Recovery (MSCR) in Modified Bitumen," Procedia Engineering 111 (August 2015): 478-484. https://doi.org/10.1016/j.proeng.2015. 07.119

13. A. Behnood, M. M. Gharehveran, F. G. Asl, and M. Ameri, "Effects of Copper Slag and Recycled Concrete Aggregate on the Properties of CIR Mixes with Bitumen Emulsion, Rice Husk Ash, Portland Cement and Fly Ash," Construction and Building Materials 96 (October 2015): 172-180. https://doi.org/10.1016/j.conbuildmat.2015.08.021

14. M. Ameri and A. Behnood, "Laboratory Studies to Investigate the Properties of CIR Mixes Containing Steel Slag as a Substitute for Virgin Aggregates," Construction and Building Materials 26, no. 1 (January 2012): 475-480. https://doi.org/ 10.1016/j.conbuildmat.2011.06.047

15. A. Behnood and M. Ameri, "Experimental Investigation of Stone Matrix Asphalt Mixtures Containing Steel Slag," Scientia Iranica 19, no. 5 (October 2012): 1214-1219. https://doi.org/10.1016/j.scient.2012.07.007

16. R. Rahbar-Rastegar, E. V. Dave, and J. S. Daniel, "Fatigue and Thermal Cracking Analysis of Asphalt Mixtures Using Continuum-Damage and Cohesive-Zone Models," Journal of Transportation Engineering, Part B: Pavements 144, no. 4 (December 2018): 04018040. https://doi.org/10.1061/JPEODX.0000066

17. X. Lu and U. Isacsson, "Rheological Characterization of Styrene-Butadiene-Styrene Copolymer Modified Bitumens," Construction and Building Materials 11, no. 1 (February 1997): 23-32. https://doi.org/10.1016/S0950-0618(96)00033-5

18. J.-S. Chen, M.-C. Liao, and M.-S. Shiah, "Asphalt Modified by Styrene-Butadiene-Styrene Triblock Copolymer: Morphology and Model,” Journal of Materials in Civil Engineering 14, no. 3 (June 2002): 224-229. https://doi.org/ 10.1061/(ASCE)0899-1561(2002)14:3(224)

19. F. J. Navarro, P. Partal, F. Martínez-Boza, C. Valencia, and C. Gallegos, "Rheological Characteristics of Ground Tire Rubber-Modified Bitumens," Chemical Engineering Journal 89, nos. 1-3 (October 2002): 53-61. https://doi.org/10. 1016/S1385-8947(02)00023-2

20. J. R. Willis, P. Turner, C. Plemmons, C. Rodezno, T. Rosenmayer, C. Daranga, and D. Carlson, "Effect of Rubber Characteristics on Asphalt Binder Properties," Road Materials and Pavement Design 14, no. 2 (September 2013): 214-230. https://doi.org/10.1080/14680629.2013.812845

21. X. Li, T. Clyne, G. Reinke, E. N. Johnson, N. Gibson, and M. E. Kutay, "Laboratory Evaluation of Asphalt Binders and Mixtures Containing Polyphosphoric Acid," Transportation Research Record: Journal of Transportation Research Board 2210, no. 1 (January 2011): 47-56. https://doi.org/10.3141/2210-06 
22. G. L. Baumgardner, "Why and How of Polyphosphoric Acid Modification - An Industry Perspective," Journal of the Association of Asphalt Paving Technologists 79 (March 2010): 663-678.

23. A. Faxina, T. Pamplona, F. Sobreiro, and G. Fabbri, "Effect of Polyphosphoric Acid on High-Temperature Properties of Bitumens from Different Crude Sources," Sixth International Conference Bituminous Mixtures and Pavements (Boca Raton, FL: CRC Press, 2015), 127.

24. N. Garg, H. Kazmee, L. Ricalde, and T. Parsons, "Rutting Evaluation of Hot and Warm Mix Asphalt Concrete under High Aircraft Tire Pressure and Temperature at National Airport Pavement and Materials Research Center," Transportation Research Record: Journal of Transportation Research Board 2672, no. 23 (September 2018): 117-127. https://doi.org/10. 1177/0361198118794293

25. K. Kanitpong and H. Bahia, "Relating Adhesion and Cohesion of Asphalts to the Effect of Moisture on Laboratory Performance of Asphalt Mixtures," Transportation Research Record: Journal of Transportation Research Board 1901, no. 1 (January 2005): 33-43. https://doi.org/10.1177/0361198105190100105

26. U. Isacsson and X. Lu, "Laboratory Investigations of Polymer Modified Bitumens," Journal of the Association of Asphalt Paving Technologists 68 (March 1999): 35-63.

27. M. Anderson, J. D’Angelo, and D. Walker, "MSCR: A Better Tool for Characterizing High Temperature Performance Properties," Asphalt 25, no. 2 (August 2010): 15-16, 18, 21-23.

28. A. Jamshidi, M. O. Hamzah, and Z. You, "Performance of Warm Mix Asphalt Containing Sasobit ${ }^{\circledR}:$ State-of-the-Art," Construction and Building Materials 38 (January 2013): 530-553. https://doi.org/10.1016/j.conbuildmat.2012.08.015

29. B. D. Prowell, G. C. Hurley, and B. Frank, Warm-Mix Asphalt: Best Practices, Quality Improvement Publication 125, 3rd ed. (Lanham, MD: National Asphalt Pavement Association, 2011).

30. Y. Wen and Y. Wang, "High-Temperature Rheological Properties of Asphalt Binders with Polymeric, Warm-Mix, and Rubber Particulate Additives," Journal of Materials in Civil Engineering 31, no. 3 (March 2019): 04018404. https://doi.org/ 10.1061/(ASCE)MT.1943-5533.0002589

31. K. L. Roja, A. Padmarekha, and J. M. Krishnan, "Rheological Investigations on Warm Mix Asphalt Binders at High and Intermediate Temperature Ranges," Journal of Materials in Civil Engineering 30, no. 4 (April 2018): 04018038. https://doi. org/10.1061/(ASCE)MT.1943-5533.0002027

32. R. Kola, Rutting Performance Prediction of Flexible Pavements Using a Unified Constitutive Relationship that Accounts for Permanent Deformation of Asphalt and Granular Layers (PhD diss., University of Kansas, 2019).

33. D. W. Christensen and D. A. Anderson, "Interpretation of Dynamic Mechanical Test Data for Paving Grade Asphalt Cements (with Discussion)," Journal of the Association of Asphalt Paving Technologists 61 (February 1992): 67-116.

34. M. Zeng, H. U. Bahia, H. Zhai, M. R. Anderson, and P. Turner, "Rheological Modeling of Modified Asphalt Binders and Mixtures (With Discussion)," Journal of the Association of Asphalt Paving Technologists 70 (March 2001): 403-441.

35. G. A. H. Reinke, "Use of the $4 \mathrm{~mm}$ DSR for Testing of Asphalt Emulsion Residue and Field Recovered Binders" (paper presentation, International Symposium on Asphalt Emulsion Technology, Arlington, VA, November 1-4, 2016).

36. D. A. Anderson, D. W. Christensen, and H. Bahia, "Physical Properties of Asphalt Cement and the Development of Performance-Related Specifications," Journal of the Association of Asphalt Paving Technologists 60 (1991): 437-475.

37. T. K. Pellinen, M. W. Witczak, and R. F. Bonaquist, “Asphalt Mix Master Curve Construction Using Sigmoidal Fitting Function with Non-linear Least Squares Optimization," in 15th Engineering Mechanics Division Conference (Reston, VA: American Society of Civil Engineers, 2012). https://doi.org/10.1061/40709(257)6

38. C. J. Glover, R. R. Davison, and N. Vassiliev, A New Method for Simulating Hot-Mix Plant Asphalt Aging (Arlington, TX: Texas Transportation Institute, the Texas A \& M University System, 2001).

39. S. W. Park and R. A. Schapery, "Methods of Interconversion between Linear Viscoelastic Material Functions. Part I-A Numerical Method Based on Prony Series," International Journal of Solids and Structures 36, no. 11 (April 1999): 16531675. https://doi.org/10.1016/S0020-7683(98)00055-9 